\title{
Comparison of NF membrane fouling and cleaning by two pretreatment strategies for the advanced treatment of antibiotic production wastewater
}

\author{
Jianxing Wang, Kun Li, Dawei Yu, Junya Zhang, Yuansong Wei, \\ Meixue Chen and Baoqing Shan
}

\begin{abstract}
The nanofiltration (NF) membrane fouling characteristics and cleaning strategies were investigated and compared for treating membrane bioreactor (MBR) effluent and MBR-granular activated carbon (GAC) effluent of an antibiotic production wastewater by DK membrane. Results showed that the fouling of treating MBR effluent was more severe than that of treating MBR-GAC effluent. After filtering for $216 \mathrm{~h}$, the difference of membrane flux decline was obvious between MBR effluent and MBR-GAC effluent, with $14.9 \%$ and $10.3 \%$ flux decline, respectively. Further study showed that organic fouling is the main NF membrane fouling in the advanced treatment of antibiotic production wastewater for both of the two different effluents. Soluble microbial by-product like and tyrosine-like substances were the dominant components in the foulants, whereas humic-like substances existing in the effluents had little contribution to the NF membrane fouling. A satisfactory efficiency of NF chemical cleaning could be obtained using combination of acid $(\mathrm{HCl}, \mathrm{pH} 2.0-2.5)$ and alkali $(\mathrm{NaOH}+$ 0.3 wt\% NaDS, pH 10.0-10.5). The favorable cleaning strategy is acid-alkali for treating the MBR-GAC effluent, while it is alkali-acid for treating the MBR effluent.

Key words | antibiotic production wastewater, cleaning, membrane fouling, nanofiltration, pretreatment
\end{abstract}

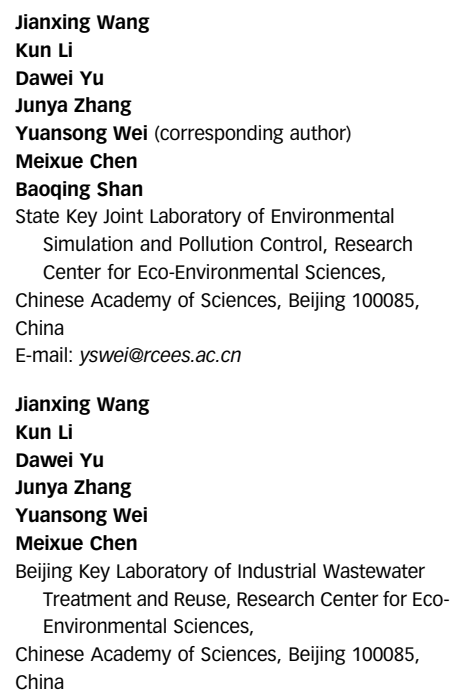

\section{INTRODUCTION}

Nanofiltration (NF) is a fast growing technology in the advanced treatment of municipal and industrial wastewater for water reuse (Aouni et al. 2009; Chon et al. 20Ir; Ellouze et al. 2012). Among the various kind of wastewaters, pharmaceutical wastewater discharged globally is not only in large amounts, but also difficult to be treated (Chelliapan et al. 2006). In our previous study, NF process was used for the advanced treatment of antibiotic production wastewater. The results showed that the NF permeate could meet China's water quality standard requirements for industrial use (GB21903-2008) (Wang et al. 20I4b; Wang et al. 20I5). However, fouling layer formation on the membrane surfaces is still a major obstacle for practical application and spreading of NF process in the advanced treatment of both the antibiotic production wastewater and other types of wastewaters (Wei et al. 20I0; Chon et al. 20I3).
According to the literature, water constituents such as particles, colloids, salts, natural organic matters, and soluble microbial products derived from biological wastewater treatment can adsorb and deposit onto membrane surface, which result in membrane fouling ( $\mathrm{Xu}$ et al. 2006). Therefore, the characteristics of the NF membrane fouling are affected by feed water composition. Xu et al. (2006) reported that the major components of foulants were polysaccharides, organic sulfonic acids, silicate colloids, $\mathrm{Si}, \mathrm{Cu}, \mathrm{Fe}, \mathrm{Zn}$ and $\mathrm{Ca}$ when treating the secondary effluent of a local municipal wastewater using NF process in Denver, CO. However, Azais et al. (2014) demonstrated that polysaccharides and humic acid were the major compounds adsorbed on the NF membrane of the municipal wastewater treatment plant (WWTP) effluent collected in the south of France. Wei et al. (20IO) showed that calcium salts and complex organic foulants containing carboxyl acid, amide, and alkyl halide functional groups were deposited 
onto the membrane surface in the advanced treatment of pharmaceutical wastewater by NF. Although there were many studies on membrane fouling of NF, the results were quite different due to different feed water qualities. Moreover, many studies focus on simulated wastewater, therefore the studies on membrane foulant identification and cleaning strategy are rather scarce in real wastewater, especially in industrial wastewater.

In addition, many studies showed that employing adequate pretreatment ahead of the membrane process could alleviate membrane fouling (Kumar et al. 2006; Al-Amoudi \& Lovitt 2007). The pretreatment methods include coagulation (Al-Amoudi \& Lovitt 2007), biofiltration (MosquedaJimenez \& Huck 2009), $\mathrm{H}_{2} \mathrm{O}_{2} / \mathrm{UV}$ (Song et al. 2004), ultrafiltration (UF) (Luo et al. 20II), activated carbon filtration (Benito-Alcazar et al. 20Io), and $\mathrm{O}_{3}$ oxidation (Flyborg et al. 20Io). Among these pretreated methods, granular activated carbon (GAC) sorption process could achieve an important reduction of the organics in the secondary effluent, which improved the feed water quality for NF process effectively. We have demonstrated that GAC sorption process was a very effective way to pretreat secondary effluent of antibiotic production wastewater in our previous study (Wang et al. 20I4a). However, the effect of GAC sorption process on NF membrane fouling should be further studied.

In this study, the fouling characteristics and cleaning strategies of NF membranes by two pretreatment strategies, membrane bioreactor (MBR) and MBR-GAC, were investigated and compared with the advanced treatment of antibiotic production wastewater. The foulants on the membrane surface were desorbed by different cleaners. Then the cleaning solutions were identified through regular chemical analysis and the three dimensional fluorescence excitationemission matrix (3D-EEM) spectra. Moreover, scanning electron microscope (SEM), atomic force microscopy (AFM), and attenuated total reflectance - Fourier transform infrared spectroscopy (ATR-FTIR) were employed to analyze the different membrane surfaces and cleaning effects.

\section{$\overline{\text { MATERIALS AND METHODS }}$}

\section{Wastewater characteristics}

The raw wastewater was the anaerobic effluent from a wastewater treatment station of a pharmaceutical company producing spiramycin in Wuxi (China). Before NF treatment, the wastewater was pretreated by a MBR and a MBR-GAC, respectively. The GAC used in this study was made from apricot shells with particle size at 10-24 mesh. The characteristics of the MBR-GAC and MBR effluent are shown in Table 1.

Table 1 | Water characteristics of NF feed and permeate in treating the MBR-GAC effluent and MBR effluent

\begin{tabular}{|c|c|c|c|c|}
\hline \multirow[b]{2}{*}{ Item } & \multicolumn{2}{|l|}{ NF feed } & \multicolumn{2}{|l|}{ NF permeate } \\
\hline & MBR-GAC & MBR & MBR-GAC & MBR \\
\hline TOC (mg/L) & $29.51 \pm 1.76$ & $104.12 \pm 3.04$ & $0.00 \pm 0.36$ & $0.79 \pm 0.33$ \\
\hline TDS (mg/L) & $3,650 \pm 170$ & $3,715 \pm 100$ & $2,500 \pm 105$ & $2,660 \pm 60$ \\
\hline $\mathrm{UV}_{254}\left(\mathrm{~cm}^{-1}\right)$ & $0.56 \pm 0.03$ & $2.19 \pm 0.07$ & $0.03 \pm 0.00$ & $0.07 \pm 0.00$ \\
\hline Turbidity (NTU) & $0.09 \pm 0.08$ & $0.14 \pm 0.13$ & $0.04 \pm 0.01$ & $0.04 \pm 0.01$ \\
\hline Colour (PCU) & $122.27 \pm 9.73$ & $828.24 \pm 33.95$ & $0.00 \pm 0.00$ & $1.67 \pm 3.83$ \\
\hline $\mathrm{K}^{+}(\mathrm{mg} / \mathrm{L})$ & $161.35 \pm 15.97$ & $154.56 \pm 9.12$ & $120.92 \pm 16.92$ & $122.97 \pm 3.29$ \\
\hline $\mathrm{Ca}^{2+}(\mathrm{mg} / \mathrm{L})$ & $276.85 \pm 16.09$ & $256.83 \pm 7.73$ & $31.92 \pm 1.26$ & $33.07 \pm 2.18$ \\
\hline $\mathrm{Na}^{+}(\mathrm{mg} / \mathrm{L})$ & $1239.37 \pm 51.72$ & $1287.16 \pm 79.32$ & $1031.50 \pm 57.55$ & $1058.42 \pm 28.21$ \\
\hline $\mathrm{Mg}^{2+}(\mathrm{mg} / \mathrm{L})$ & $33.63 \pm 2.32$ & $30.96 \pm 1.14$ & $1.18 \pm 0.12$ & $1.07 \pm 0.13$ \\
\hline $\mathrm{Cl}^{-}(\mathrm{mg} / \mathrm{L})$ & $2523.69 \pm 141.53$ & $2382.63 \pm 154.55$ & $1575.89 \pm 159.44$ & $1449.13 \pm 118.49$ \\
\hline $\mathrm{NO}_{2}^{-}(\mathrm{mg} / \mathrm{L})$ & $7.32 \pm 1.56$ & $5.97 \pm 1.87$ & $5.16 \pm 0.54$ & $4.80 \pm 1.55$ \\
\hline $\mathrm{NO}_{3}^{-}(\mathrm{mg} / \mathrm{L})$ & $1275.63 \pm 65.85$ & $1469.09 \pm 94.86$ & $909.25 \pm 90.41$ & $1062.22 \pm 111.68$ \\
\hline $\mathrm{PO}_{4}^{3-}(\mathrm{mg} / \mathrm{L})$ & $13.08 \pm 0.76$ & $25.86 \pm 1.04$ & $0.50 \pm 0.07$ & $0.74 \pm 0.09$ \\
\hline $\mathrm{SO}_{4}^{2-}(\mathrm{mg} / \mathrm{L})$ & $157.74 \pm 27.80$ & $74.07 \pm 5.63$ & $1.61 \pm 0.49$ & $0.32 \pm 0.29$ \\
\hline $\mathrm{CO}_{3}^{2-}(\mathrm{mg} / \mathrm{L})$ & 2.11 & 6.15 & 2.76 & 5.18 \\
\hline
\end{tabular}




\section{Experimental setup}

NF tests were carried out by using a bench-plant (Shanghai Shiyuan Bioengineering Equipment Co., China) equipped with three pressure vessels for $1.8 \times 12$ inches spiral-wound membrane modules. DK membrane (DK 1812C-34D), which was provided by GE Osmonics, was employed according to our previous study (Wang et al. 2014a). Both permeate and retentate were circulated back to the feed reservoir. NF tests were conducted at pressure of $1.0 \mathrm{MPa}$ and crossflow velocity of $8.0 \mathrm{~L} / \mathrm{min}$ at $25^{\circ} \mathrm{C}$. Each test was carried out for $216 \mathrm{~h}$.

To analyze the membrane fouling, NF fouling tests were performed by using a cross-flow flat-sheet membrane test unit (SEPA CF II, GE Osmonics). A flat sheet NF membrane of DK was used. The surface area of the NF membrane was $139 \mathrm{~cm}^{2}$. Each fouling test was carried out for $45 \mathrm{~h}$ in treating the MBR effluent and MBR-GAC effluent as mentioned above. The permeate and retentate were also circulated back to the feed reservoir. The operating parameters were the same as for the NF tests (i.e. TMP $1.0 \mathrm{MPa}, 25^{\circ} \mathrm{C}$ ). After $\mathrm{NF}$ fouling test, the fouled flat membrane was divided into six parts. Five of these parts were soaked with deionized (DI) water, acid ( $\mathrm{HCl}, \mathrm{pH} 2.0-2.5)$, alkali $(\mathrm{NaOH}+0.3 \mathrm{wt} \%$ NaDS, pH 10.0-10.5), acid-alkali (soaking with acid firstly and then with alkali), alkali-acid (soaking with alkali firstly and then with acid) for $24 \mathrm{~h}$, respectively. The NF membranes and cleaning solutions were further analyzed to investigate the fouling characteristic and cleaning strategy.

\section{Analysis}

Total organic carbon (TOC) was determined by a TOCVCPH (Shimadzu, Japan). UV $_{254}$ was measured by an ultraviolet and visible spectrophotometer (Spectrum Laboratory 752sp, Lengquang Tech, China). A color meter (HI 96727, Hanna, Italy) and a turbidity meter (Turb 550, WTW, Germany) were used to measure color and turbidity, respectively. Total dissolved solids (TDS) was measured with a conductivity/TDS meter (HI4321, Hanna, Italy). The contents of $\mathrm{Ca}^{2+}, \mathrm{Na}^{+}, \mathrm{K}^{+}$, and $\mathrm{Mg}^{2+}$ were analyzed by an inductively coupled plasma optical emission spectroscopy (Optima $2100 \mathrm{DV}$, Perkin Elmer, USA). The anions $\left(\mathrm{Cl}^{-}\right.$, $\mathrm{NO}_{3}^{-}, \mathrm{NO}_{2}^{-}, \mathrm{SO}_{4}^{2-}$, and $\mathrm{PO}_{4}^{3-}$ ) were determined using an ion chromatography (ICS-1000, Dionex, USA).

A fluorescence spectrophotometer (F-7000, Hitachi, Japan) was used to investigate major components and the complexity of organic matter that were contained in the NF feed streams and cleaning solutions.
SEM (S-3000N, Hitachi, Japan) analysis was carried out to observe the surfaces of virgin and fouled NF membranes. All samples were freeze-dried for $24 \mathrm{~h}$.

NF membrane surface roughness was determined using an AFM (NanoScope IIIa, Digital Instruments, USA). Imaging was performed in tapping mode on an area of $2 \mu \mathrm{m} \times$ $2 \mu \mathrm{m}$. Each sample was measured three times.

ATR-FTIR was performed using a Fourier transform infrared spectrometer (Nicolet 8700, Thermo Electron Corporation, USA) with a resolution of $4 \mathrm{~cm}^{-1}$ in the range $400-4,000 \mathrm{~cm}^{-1}$ to obtain information about the functional groups of the membrane surfaces.

\section{RESULTS AND DISCUSSION}

\section{Performance of NF membrane}

Water characteristics of NF feed and permeate in treating MBRGAC effluent and MBR effluent are shown in Table 1. As shown in Table 1, excellent water quality could be obtained using NF process for the treatment of both MBR-GAC effluent and MBR effluent. The TOC of NF permeates were lower than $1.0 \mathrm{mg} / \mathrm{L}$, which illustrated that there was no significant effect on NF permeates of different pretreatment processes. However, the difference of membrane flux decline was obvious between MBR-GAC effluent and MBR effluent, with 10.3\% and 14.9\% membrane flux decline, respectlively, at the end (Figure 1). For the initial permeate flux for treating MBR and MBR-GAC effluents was nearly at the same level, i.e. $69.38 \mathrm{~L} / \mathrm{h} \cdot \mathrm{m}^{2}$ and $72.19 \mathrm{~L} / \mathrm{h} \cdot \mathrm{m}^{2}$. We concluded that the MBR effluent suffered more serious fouling than the MBR-GAC effluent when treated by the NF process. As the main difference of the two feed streams was TOC concentration shown in Table 1 (i.e.

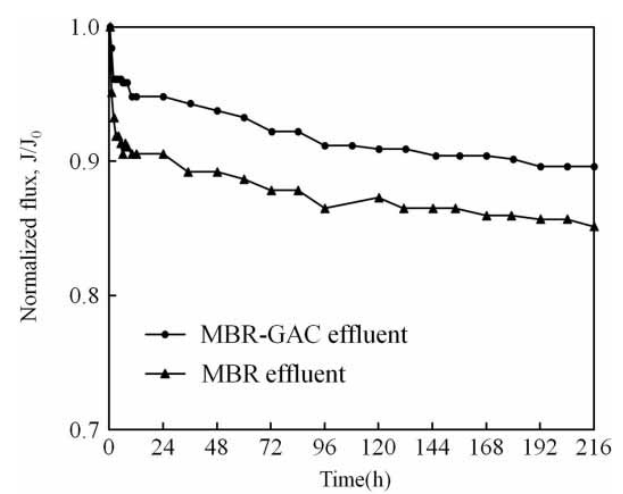

Figure 1 | Changes of NF membrane flux decline for treating the MBR-GAC effluent and MBR effluent. 
$29.51 \pm 1.76 \mathrm{mg} / \mathrm{L}$ and $104.12 \pm 3.04 \mathrm{mg} / \mathrm{L}$, respectively), we can infer that organics is the primary cause of this phenomenon. In addition, Figure 1 shows that the rapid decline of flux occurred at the initial stage of NF treatment, which was unlike Ang's study (Ang et al. 20п). This may be also caused by the influence of the organics in the feed streams.

\section{NF membrane morphological analysis}

The samples of virgin and fouled NF membranes through NF fouling tests were tested with SEM and AFM, respectively (Figures 2 and 3). As shown in Figure 2, the surface of virgin NF membrane was rather clean and smooth. In contrast, it was obvious that the NF membrane surface was seriously fouled for treating these two effluents after fouling tests. A cake layer was formed by the foulants attached to the NF membrane surface.

The mean roughnesses of the virgin and fouled NF membrane changed apparently in Figure 3, i.e., the mean roughnesses of the virgin NF membrane, fouled NF membrane treating the MBR-GAC effluent, and fouled NF membrane treating the MBR effluent were $11.186 \mathrm{~nm}$, $23.710 \mathrm{~nm}$, and $34.638 \mathrm{~nm}$, respectively. As the surface of DK membrane was rather smooth, the foulants built up on the membrane surfaces and resulted in an increase in surface roughness. This result was consistent with Xu's study (Xu et al. 2006). The changes of roughness also showed that it suffered worse fouling from treating the MBR effluent compared with the MBR-GAC effluent.

\section{Identification of membrane foulant and cleaning strategies}

\section{Characterization of the foulant desorbed by different cleaning strategies}

In order to identify the foulant composition of the fouling layer, the cleaning solutions by different cleaners was analyzed through regular chemical analysis and 3D-EEM. The extent of organics desorbed from the fouled membrane was determined by TOC measurements using the different cleaning strategies described above (Figure 4). Higher concentrations of TOC were detected desorbing by alkali cleaning, acid-alkali cleaning and alkali-acid cleaning. However, none of the inorganic ions (including $\mathrm{Ca}^{2+}, \mathrm{Mg}^{2+}, \mathrm{SO}_{4}^{2-}$ ) were found in each cleaning solution. This demonstrated that organics were the dominant factor of membrane fouling in the advanced treatment of antibiotic production wastewater by NF process. Furthermore, on the basis of TOC concentrations in the desorption solutions, the favorable cleaning strategy is acid-alkali when treating the MBR-GAC effluent, while it is alkali-acid when treating the MBR effluent. This might be due to the different composition of the two effluents, which resulted in different composition of membrane foulants. Generally, acid cleaning
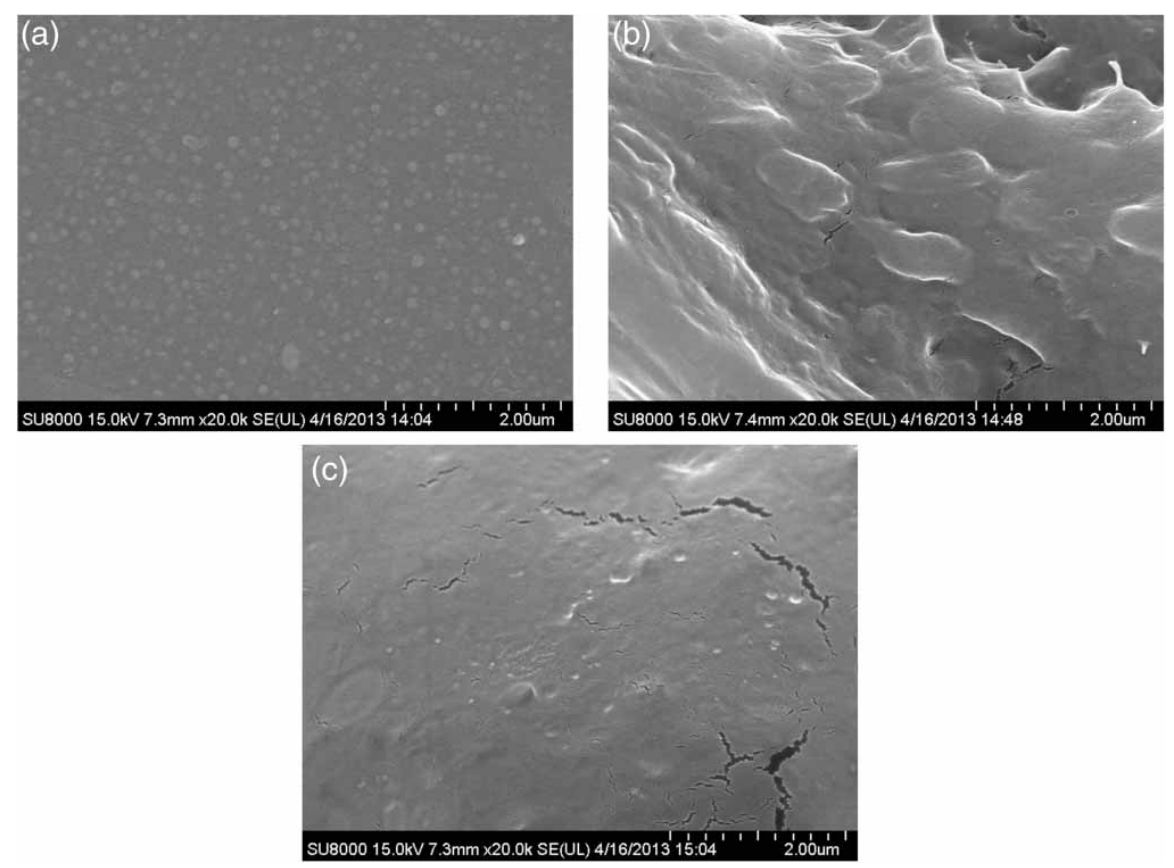

Figure 2 | Comparison of SEM photos of different NF membranes: (a) virgin membrane, (b) fouled membrane treating MBR-GAC effluent, and (c) fouled membrane treating MBR effluent. 
(a)

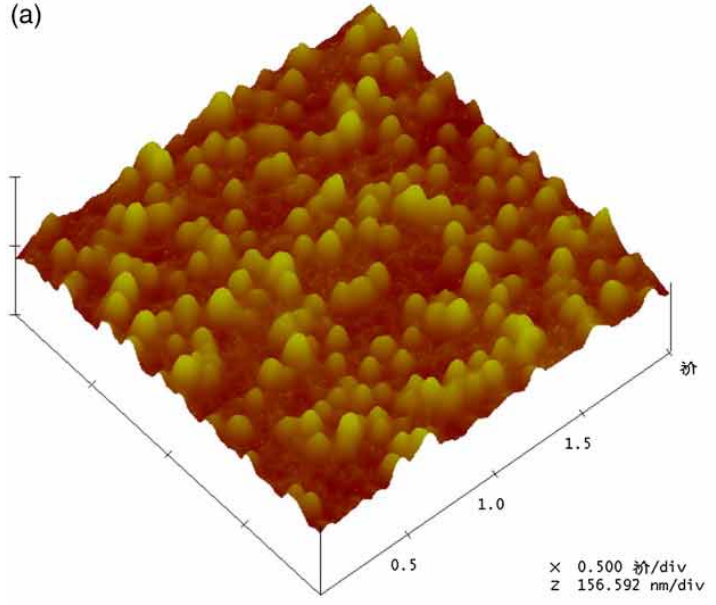

(b)

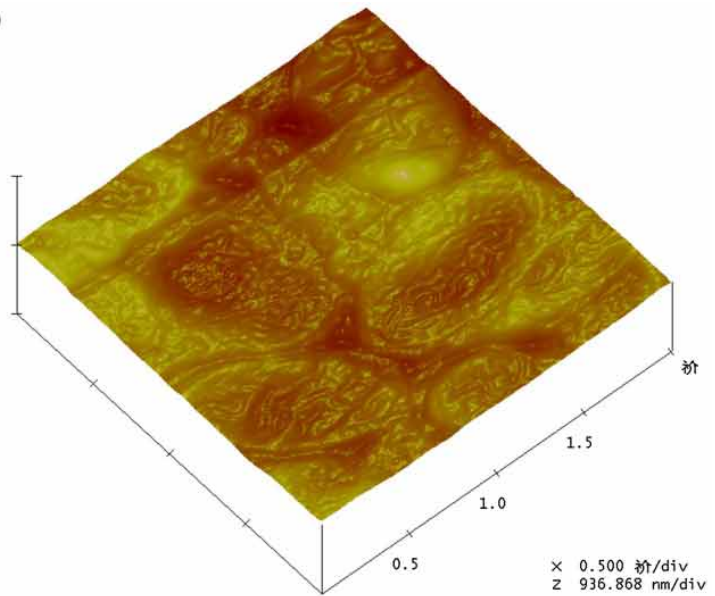

(c)

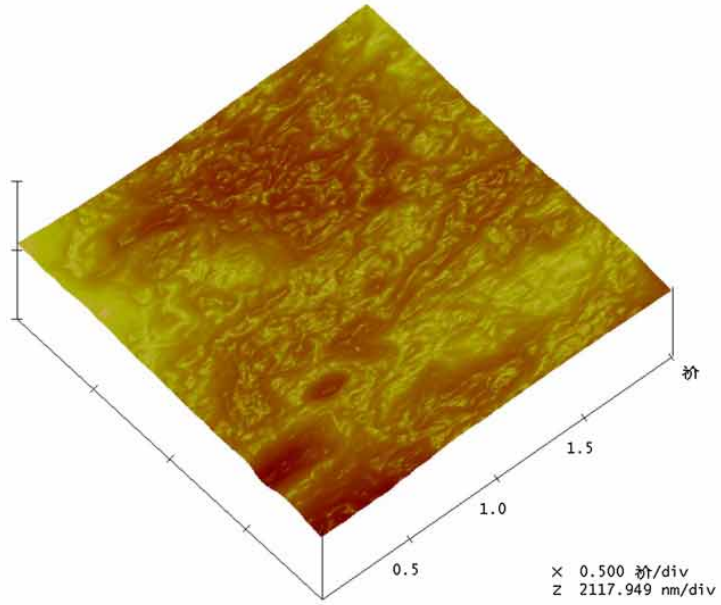

Figure 3 | Comparison of AFM photos of different NF membranes: (a) virgin membrane, (b) fouled membrane treating MBR-GAC effluent, and (c) fouled membrane treating MBR effluent.
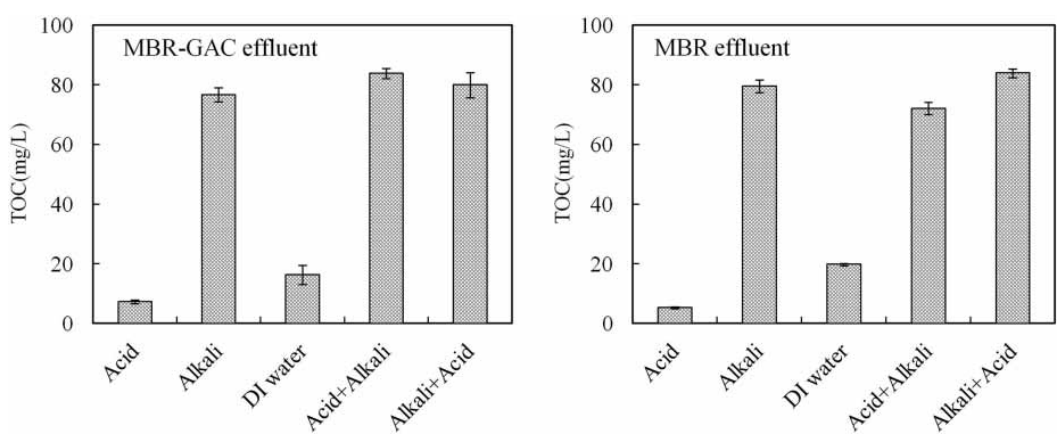

Figure 4 | TOC concentrations using the cleaning solutions for treating MBR-GAC effluent and MBR effluent.

is suitable for the removal of precipitated salts, while alkali cleaning is used to remove adsorbed organics. Xiao et al. (20I2) also demonstrated that $\mathrm{HCl}$ solution could remove the substance of aromatic protein, while $\mathrm{NaOH}$ solution could remove both aromatic protein and other organics, such as soluble microbial by-product (SMP)-like substance. The different effectivity between alkali-acid and acid-alkali might due to the different composition of membrane foulants. As shown in Table 1, the inorganic ions concentrations of the two effluents were at the same level, whereas the organic concentrations were obviously different. This led to different inorganic/ organic ratio of the two effluents. Kappel et al. (2014) showed that change of $\mathrm{Ca}^{2+} / \mathrm{TOC}$ ratio could induce different membrane fouling characteristics. Therefore, the different 
inorganic/organic ratio of the two effluents might lead to different membrane fouling characteristics, which influenced the cleaning strategies and the difference between alkali-acid and acid-alkali in treating the two effluents.

The 3D-EEMs is a collection of a series of emission spectra over a range of excitation wavelengths, which can be used to identify the fluorescent compounds present in complex mixtures (Wang et al. 2009). Chen et al. (2003) divided the EEM spectra into five regions, including humic acid-like, fulvic acid-like, tyrosine-like, tryptophan-like, and soluble microbial by-product-like organics, respectively (Table 2). In this study, 3D-EEMs were employed to identify the organics in feed streams and membrane foulants, and the results are illustrated in Figure 5 and Table 2.

As shown in Figure 5 and Table 2, strong humic-like fluorescence of Peak A was found both in the
MBR-GAC effluent and MBR effluent. The concentration of humic-like substances in the MBR effluent was much higher than in MBR-GAC effluent, with intensities of $15,496 \mathrm{~nm}$ and 3,242 nm, respectively. However, cleaning solutions showed two other maximum peaks (Peak B and Peak C) which corresponded to SMP-like and tyrosine-like substances for treating these two effluents. This demonstrated SMP-like and tyrosine-like substances were the dominant components in the foulants, whereas humic-like substances had little contribution to the NF membrane fouling, which was consistent with other literature (Zazouli et al. 2010). Moreover, the concentrations of SMP-like and tyrosine-like substances in cleaning solution treating the MBR effluent were much higher than that of treating the MBR-GAC effluent as shown in Table 2, which further demonstrated that fouling of MBR effluent was more severe.

Table 2 | EEM peaks and intensities in the different solutions

\begin{tabular}{|c|c|c|c|c|c|c|c|c|c|}
\hline \multirow[b]{2}{*}{ EEM region } & \multirow[b]{2}{*}{ Rang (EX/Em) } & \multicolumn{2}{|c|}{ MBR-GAC effluent } & \multicolumn{2}{|l|}{ MBR effluent } & \multicolumn{2}{|c|}{$\begin{array}{l}\text { Cleaning solution treating } \\
\text { MBR-GAC effluent }\end{array}$} & \multicolumn{2}{|c|}{$\begin{array}{l}\text { Cleaning solution treating } \\
\text { MBR effluent }\end{array}$} \\
\hline & & Rang (EX/Em) & Inten. max. & Rang (EX/Em) & Inten. max. & Rang (EX/Em) & Inten. max. & Rang (Ex/Em) & Inten. max. \\
\hline Tryptophan-like & $<250 / 280-330$ & - & - & - & - & - & - & - & - \\
\hline Tyrosine-like & $<250 / 330-380$ & - & - & - & - & $230 / 330$ & 2,682 & $225 / 335$ & 4,102 \\
\hline SMP-like & $>250 / 280-380$ & - & - & - & - & $280 / 330$ & 8,774 & $285 / 335$ & 9,360 \\
\hline Humic acid-like & $>250 />380$ & $325 / 400$ & 3,242 & $355 / 405$ & 15,496 & - & - & - & - \\
\hline Fulvic acid-like & $<250 />380$ & - & - & - & - & - & - & - & - \\
\hline
\end{tabular}
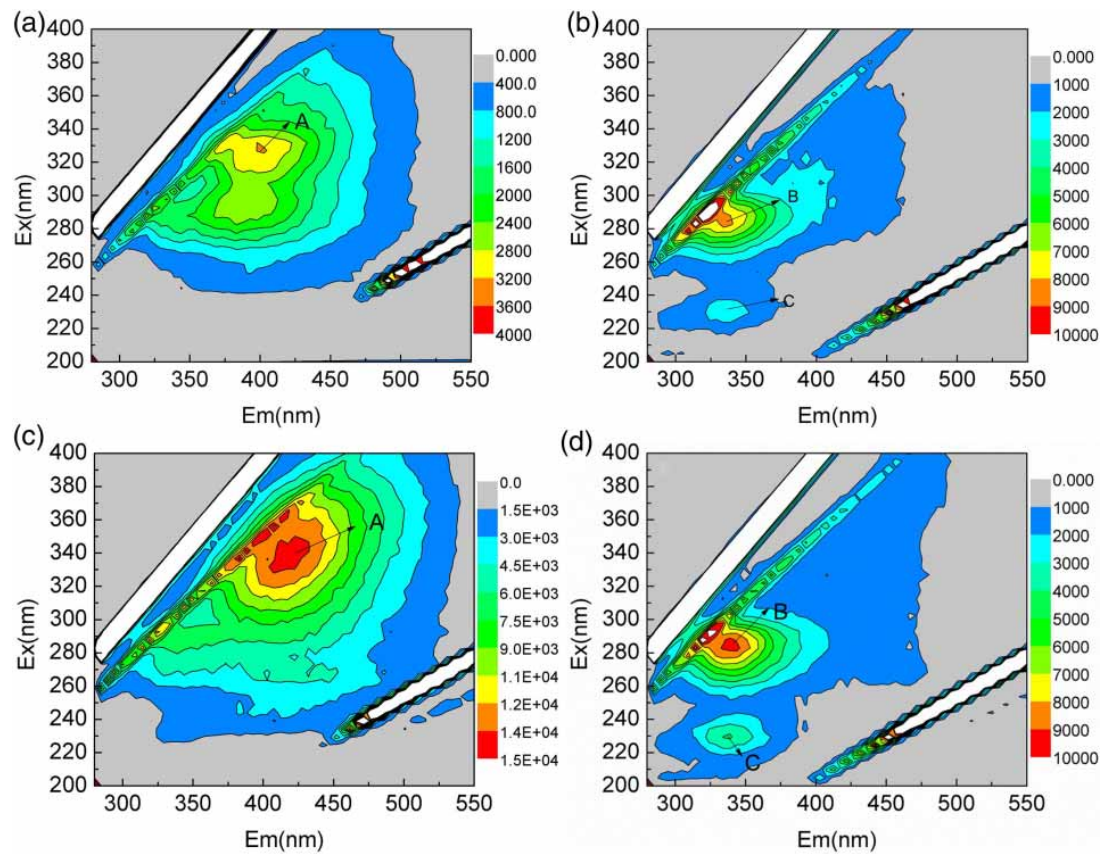

Figure 5 | 3D-EEMs in the different solutions: (a) MBR-GAC effluent, (b) cleaning solution treating MBR-GAC effluent, (c) MBR effluent, and (d) cleaning solution treating MBR effluent. 

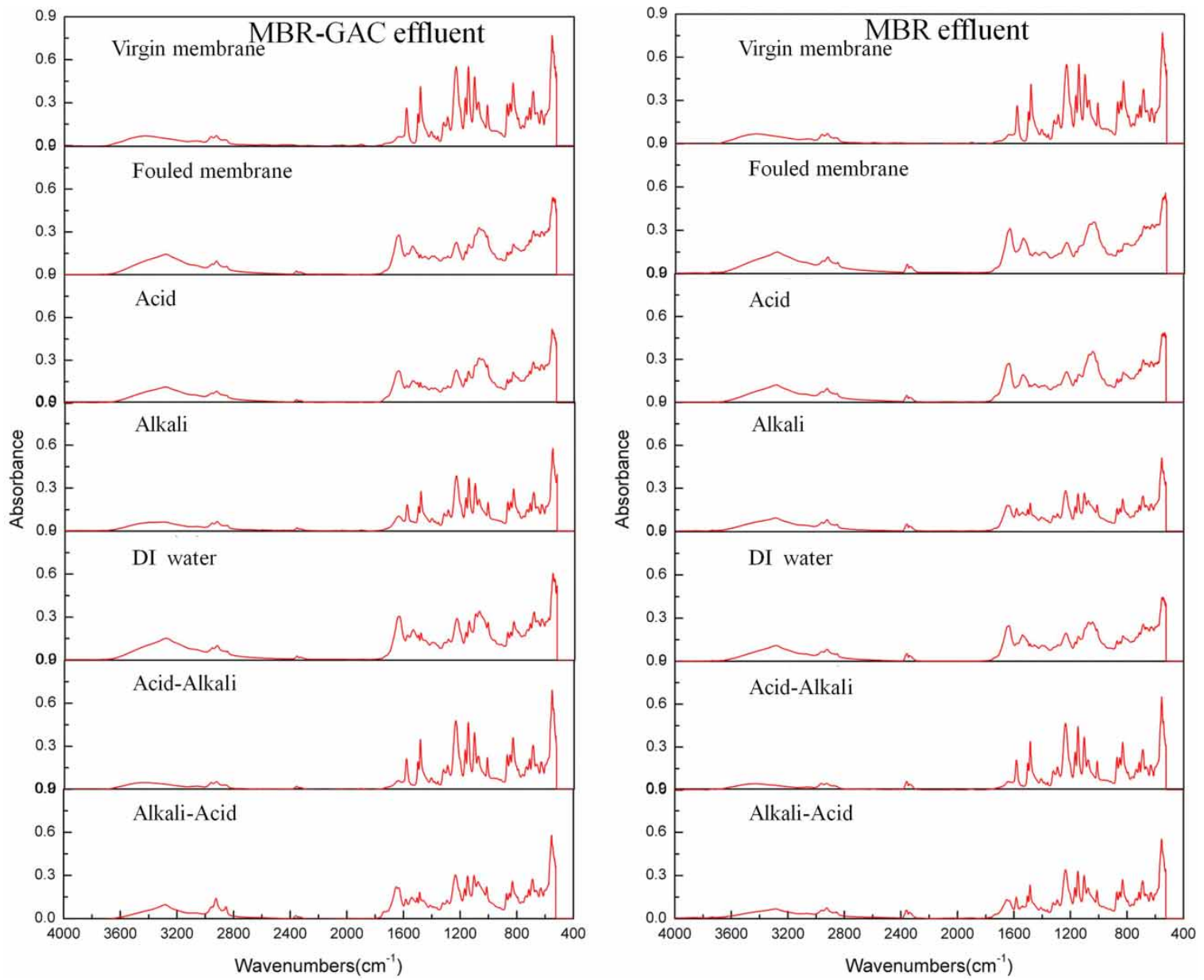

Figure 6 | ATR-FTIR spectrums of different NF membranes for treating MBR-GAC effluent and MBR effluent.

\section{ATR-FTIR analysis of different NF membranes}

The virgin, fouled and cleaned NF membranes had been investigated by ATR-FTIR spectral analysis as presented in Figure 6. As shown in Figure 6, the spectra of the virgin DK membrane were similar to the specific ATR-FTIR absorbance peaks typical for polyamide membranes (Mo et al. 20Io). After fouled for $45 \mathrm{~h}$, the peaks of virgin membranes decreased in both the absorbance intensity and peak quantity, suggesting that the membranes were severely fouled. It is shown that there was poor cleaning effect by DI water or acid separately. However, cleaning by alkali could obtain a perfect result, which also demonstrated that the main foulants of the fouling layer were organics. After cleaning by acid and alkali, there were significant similarities in the spectra obtained for the cleaned membrane with the virgin membrane, which proved that it could get satisfactory cleaning performance through combining acid and alkali cleaning.

\section{CONCLUSIONS}

Organic fouling is the main membrane fouling in the advanced treatment of antibiotic production wastewater by NF process. The membrane fouling of treating the MBR effluent was worse than that of treating the MBR-GAC effluent. SMP-like and tyrosine-like substances were the dominant components in the foulants treating these two effluents, whereas humic-like substances existing in the effluents had little contribution to the NF membrane fouling. The favorable cleaning strategies is acid $(\mathrm{HCl}, \mathrm{pH} 2.0-2.5)$-alkali $(\mathrm{NaOH}+$ $0.3 \mathrm{wt} \%$ NaDS, pH 10.0-10.5) for treating the MBR-GAC effluent, while it is alkali-acid for treating the MBR effluent.

\section{ACKNOWLEDGEMENTS}

Financial support provided by the National Major Science \& Technology Projects for Water Pollution Control and 
Management (No. 2012ZX07203-002 and 2015ZX07203005), National Science Foundation for Post-doctoral Scientists of China (No. 2015M571140) and National High Technology Research and Development Program of China (No. 2009AA063901) are gratefully acknowledged.

\section{REFERENCES}

Al-Amoudi, A. \& Lovitt, R. W. 2007 Fouling strategies and the cleaning system of NF membranes and factors affecting cleaning efficiency. J. Membrane Sci. 303 (1-2), 6-28.

Ang, W. S., Yip, N. Y., Tiraferri, A. \& Elimelech, M. 2oII Chemical cleaning of RO membranes fouled by wastewater effluent: achieving higher efficiency with dual-step cleaning. J. Membrane Sci. 382 (1-2), 100-106.

Aouni, A., Fersi, C., Ali, M. \& Dhahbi, M. 2009 Treatment of textile wastewater by a hybrid electrocoagulation/ nanofiltration process. J. Hazard Mater. 168 (2-3), 868-874.

Azais, A., Mendret, J., Gassara, S., Petit, E., Deratani, A. \& Brosillon, S. 2014 Nanofiltration for wastewater reuse: counteractive effects of fouling and matrice on the rejection of pharmaceutical active compounds. Sep. Purif. Technol. 133, 313-327.

Benito-Alcazar, C., Vincent-Vela, M. C., Gozalvez-Zafrilla, J. M. \& Lora-Garcia, J. 2oIo Study of different pretreatments for reverse osmosis reclamation of a petrochemical secondary effluent. J. Hazard Mater. 178 (1-3), 883-889.

Chelliapan, S., Wilby, T. \& Sallis, P. J. 2006 Performance of an upflow anaerobic stage reactor (UASR) in the treatment of pharmaceutical wastewater containing macrolide antibiotics. Water Res. 40 (3), 507-516.

Chen, W., Westerhoff, P., Leenheer, J. A. \& Booksh, K. 2003 Fluorescence excitation - Emission matrix regional integration to quantify spectra for dissolved organic matter. Environ. Sci. Technol. 37 (24), 5701-5710.

Chon, K., Sarp, S., Lee, S., Lee, J. H., Lopez-Ramirez, J. A. \& Cho, J. 2oII Evaluation of a membrane bioreactor and nanofiltration for municipal wastewater reclamation: trace contaminant control and fouling mitigation. Desalination 272 (1-3), 128-134.

Chon, K., Cho, J. \& Shon, H. K. 2013 Fouling characteristics of a membrane bioreactor and nanofiltration hybrid system for municipal wastewater reclamation. Bioresource Technol. 130, 239-247.

Ellouze, E., Tahri, N. \& Ben Amar, R. 2012 Enhancement of textile wastewater treatment process using nanofiltration. Desalination 286, 16-23.

Flyborg, L., Bjorlenius, B. \& Persson, K. M. 20Io Can treated municipal wastewater be reused after ozonation and nanofiltration? Results from a pilot study of pharmaceutical removal in Henriksdal WWTP, Sweden. Water Sci. Technol. 61 (5), 1113-1120.
Kappel, C., Kemperman, A., Temmink, H., Zwijnenburg, A., Rijnaarts, H. \& Nijmeijer, K. 20I4 Impacts of NF concentrate recirculation on membrane performance in an integrated MBR and NF membrane process for wastewater treatment. J. Membrane Sci. 453, 359-368.

Kumar, M., Adham, S. S. \& Pearce, W. R. 2006 Investigation of seawater reverse osmosis fouling and its relationship to pretreatment type. Environ. Sci. Technol. 40 (6), 2037-2044.

Luo, J., Ding, L., Qi, B., Jaffrin, M. Y. \& Wan, Y. 20II A two-stage ultrafiltration and nanofiltration process for recycling dairy wastewater. Bioresource Technol. 102 (16), 7437-7442.

Mo, Y. H., Chen, J. H., Xue, W. C. \& Huang, X. 2oro Chemical cleaning of nanofiltration membrane filtrating the effluent from a membrane bioreactor. Sep. Purif. Technol. 75 (3), 407-414.

Mosqueda-Jimenez, D. B. \& Huck, P. M. 2009 Effect of biofiltration as pretreatment on the fouling of nanofiltration membranes. Desalination 245 (1-3), 60-72.

Song, W., Ravindran, V., Koel, B. E. \& Pirbazari, M. 2004 Nanofiltration of natural organic matter with $\mathrm{H}_{2} \mathrm{O}_{2}$ /UV pretreatment: fouling mitigation and membrane surface characterization. J. Membrane Sci. 241 (1), 143-160.

Wang, Z. W., Wu, Z. C. \& Tang, S. J. 2009 Extracellular polymeric substances (EPS) properties and their effects on membrane fouling in a submerged membrane bioreactor. Water Res. 43 (9), 2504-2512

Wang, J. X., Wei, Y. S. \& Cheng, Y. T. 2or4a Advanced treatment of antibiotic wastewater by nanofiltration: membrane selection and operation optimization. Desalin. Water Treat. 52 (40-42), 7575-7585.

Wang, J. X., Wei, Y. S., Li, K., Cheng, Y. T., Li, M. Y. \& Xu, J. G. 2014b Fate of organic pollutants in a pilot-scale membrane bioreactornanofiltration membrane system at high water yield in antibiotic wastewater treatment. Water Sci. Technol. 69 (4), 876-881.

Wang, J. X., Li, K., Wei, Y. S., Cheng, Y. T., Wei, D. B. \& Li, M. Y. 20I5 Performance and fate of organics in a pilot MBR-NF for treating antibiotic production wastewater with recycling NF concentrate. Chemosphere 121, 92-100.

Wei, X. Y., Wang, Z., Fan, F. H., Wang, J. X. \& Wang, S. C. 2010 Advanced treatment of a complex pharmaceutical wastewater by nanofiltration: membrane foulant identification and cleaning. Desalination 251 (1-3), 167-175.

Xiao, P., Xiao, F., Wang, D. S., Qin, T. \& He, S. P. 2012 Investigation of organic foulants behavior on hollow-fiber UF membranes in a drinking water treatment plant. Sep. Purif. Technol. 95, 109-117.

Xu, P., Drewes, J. E., Kim, T. U., Bellona, C. \& Amy, G. 2006 Effect of membrane fouling on transport of organic contaminants in NF/RO membrane applications. J. Membrane Sci. 279 (1-2), 165-175.

Zazouli, M. A., Nasseri, S. \& Ulbricht, M. 2010 Fouling effects of humic and alginic acids in nanofiltration and influence of solution composition. Desalination 250 (2), $688-692$

First received 28 July 2015; accepted in revised form 23 December 2015. Available online 9 February 2016 